\title{
Correction to: Association of PM2.5 concentration with health center outpatient visits for respiratory diseases of children under 5 years old in Lima, Peru
}

Jennifer Estefanía Davila Cordova ${ }^{1 *}$, Vilma Tapia Aguirre', Vanessa Vasquez Apestegui ${ }^{1}$, Luis Ordoñez Ibarguen², Bryan N. Vu ${ }^{3}$, Kyle Steenland ${ }^{3}$ and Gustavo F. Gonzales ${ }^{1}$

\section{Correction to: Environ Health (2020) 19:7 \\ https://doi.org/10.1186/s12940-020-0564-5}

The original version of this article [1], published on 15 January 2020, contained incorrect name of the coauthor. In this Correction the affected part of the article is shown.

Incorrect co-author's name:

Gustavo F. Gonzales Rengifo

Correct co-author's name:

Gustavo F. Gonzales

The original article has been corrected.

\begin{abstract}
Author details
${ }^{1}$ Faculty of Sciences and Philosophy, and Laboratory of Investigation and Development, Universidad Peruana Cayetano Heredia, Lima, Peru. ${ }^{2}$ National Center for Epidemiology, Prevention and Control of Diseases, Minsa, Peru. ${ }^{3}$ Department of Environmental Health, Rollins School of Public Health, Emory University, Atlanta, GA 30322, USA.
\end{abstract}

Published online: 30 January 2020

\section{Reference}

1. Davila Cordova JE, et al. Association of PM2.5 concentration with health center outpatient visits for respiratory diseases of children under 5 years old in Lima, Peru. Environ Health. 2020;19:7. https://doi.org/10.1186/s12940-020-0564-5.

Full list of author information is available at the end of the article 